\title{
REIMAGINANDO OS CONTORNOS DE GÊNERO: INTERVENÇÕES ARTÍSTICAS NO CAMPO DAS MASCULINIDADES
}

Andréa Gill*

Isabela Souza da Silva**

Marta Fernández***

Tatiana Moura***

Neste artigo situa-se a discussão sobre gênero e masculinidades no contexto das suas qualificações e desqualificações hierárquicas da nossa humanidade. Partindo da violência estrutural e estruturante que marca as pós-colónias, como o Brasil, questionam-se as dinâmicas de violências raciais-genderizadas que reproduzem as normas, padrões e pactos imbricados de masculinidades hegemónicas. Desta forma, propõe-se um diálogo com práticas artístico-culturais periferizadas que redimensionam como incorporamos tais idealizações de gênero. Para esse fim, centramo-nos na produção do espetáculo Na Manhadesenvolvido no âmbito da residência artística do projeto de pesquisa-ação GlobalGRACE (Gênero e Culturas Globais de Igualdade), com a Companhia de Dança Passinho Carioca e sob a direção do coletivo de dança Mulheres ao Vento no Rio de Janeiro.

Palavras-chave: masculinidades, periferias, arte, passinho, decolonial.

Instituto de Relações Internacionais, Pontíficia Universidade Católica do Rio de Janeiro (PUC-Rio) e UNIperiferias. Rio de Janeiro - RJ, Brasil, CEP: 22451-900.

Endereço postal: IRI - PUC-Rio, R. Marquês de São Vicente, 225, Vila dos Diretórios, Casa 20, Gávea, Rio de Janeiro - RJ, Brasil, CEP: 22451-900.

Endereço eletrónico: andrea.b.gill@gmail.com

** Universidade Federal Fluminense (UFF) e Observatório de Favelas. Niterói - RJ, Brasil, CEP: 24220-900.

Endereço postal: Observatório de Favelas, Rua Teixeira Ribeiro, 535, Maré, Rio de Janeiro - RJ, CEP: 21044-251.

Endereço eletrónico: isabela@observatoriodefavelas.org.br

**** Instituto de Relações Internacionais, Pontíficia Universidade Católica do Rio de Janeiro (PUC-Rio). Rio de Janeiro - RJ, Brasil, CEP: 22451-900.

Endereço postal: IRI - PUC-Rio, R. Marquês de São Vicente, 225, Vila dos Diretórios, Casa 20, Gávea, Rio de Janeiro - RJ, Brasil, CEP: 22451-900.

Endereço eletrónico: martafygarcia@gmail.com

***** Centro de Estudos Sociais da Universidade de Coimbra (3000-104 Coimbra, Portugal) e Instituto Promundo (CEP: 70711-903 Brasília, DF - Brasil).

Endereço postal: Centro de Estudos Sociais, Colégio de São Jerónimo, 3000-104 Coimbra, Portugal.

Endereço eletrónico: t.moura@promundoglobal.org 


\title{
Abstract \\ Reimagining Gender: Artistic Interventions in the Field of Masculinities
}

In this paper we situate the discussion on gender and masculinities in the context of their hierarchical qualifications and disqualifications of our humanness. Taking as a point of departure the structural and structuring violence that marks postcolonies, such as Brazil, we question the dynamics of racial-gendered violence that reproduce the imbricated norms, standards and pacts of hegemonic masculinities. In this way, we propose a dialogue with peripherized artistic-cultural practices that reshape how we incorporate such idealizations of gender. To this end, we focus on the production of the performance $\mathrm{Na}$ Manha-developed within the scope of the artistic residency of the GlobalGRACE (Global Gender and Cultures of Equality) research-action project, with the Dance Company Passinho Carioca and under the direction of the dance collective Mulheres ao Vento (Women in the Wind) in Rio de Janeiro.

Keywords: masculinities, peripheries, art, passinho, decolonial.

\begin{abstract}
Resumen
Reimaginando los contornos del género: intervenciones artísticas en el ámbito de las masculinidades

Em este trabajo situamos la discusión sobre género y masculinidades en el contexto de sus calificaciones y descalificaciones jerárquicas de nuestra humanidad. Tomando como punto de partida la violencia estructural y estructurante que marca las poscolonias, como Brasil, cuestionamos las dinámicas de violencias raciales-generizadas que reproducen las normas, estándares y pactos imbricados de las masculinidades hegemónicas. De esta forma, proponemos un diálogo con prácticas artístico-culturales periferizadas que redimensionan cómo incorporamos tales idealizaciones de género. Para este propósito, nos centramos en la producción de la performance $\mathrm{Na} \mathrm{Manha} \mathrm{-} \mathrm{elaborado} \mathrm{en} \mathrm{el} \mathrm{contexto} \mathrm{de} \mathrm{la} \mathrm{residencia}$ artística del proyecto de investigación-acción GlobalGRACE (Género y Culturas Globales de Igualdad), con la Compañía de Danza Passinho Carioca y bajo la dirección del colectivo Mulheres ao Vento (Mujeres al viento) en Río de Janeiro.
\end{abstract}

Palabras clave: Masculinidades, periferias, arte, passinho, decolonial.

\section{Introdução}

A cidade do Rio de Janeiro foi estruturada com base numa profunda desigualdade socioterritorial que lançou e segregou a sua população negra para/nas suas margens, favelas e periferias, interditando o seu direito à cidade, mobilidade e vida, produzindo o que os movimentos negros vêm denunciando como a farsa da abolição. Sustentada e reproduzida violentamente pelas instituições do Estado como a polícia e o exército, esta desigualdade que atravessa o território brasileiro - e o da Améfrica Ladina, como Lélia Gonzalez (1988) denominou o nosso continente - expressa-se e renova-se diariamente na distribuição desigual de recursos materiais, políticos, simbólicos e culturais através da cidade, para além de violências das mais variadas formas e escalas. Esta ordem urbana injusta, bifurcada e hierárquica, por sua vez, não se mantém como obra do acaso. A sua reprodução e normalização resultam de um projeto de necropolítica (Mbembe 2011) que tem 
como objetivo matar económica, social e fisicamente uma parcela significativa da população negra, pobre e periférica, como condição de possibilidade de sustentar populações privilegiadas e brancas pelo projeto moderno colonial europeu.

O confinamento da população negra no que Frantz Fanon (2004) chamou de zona do não ser, sujeita a processos seculares de precarização e aniquilação, depende de incursões diárias de brutalidade policial e de racismo institucional forjados no seio de uma sociedade escravista. Ao mesmo tempo em que o Estado se omite, ele se excede. Se, por um lado, ele se retira de territórios onde se habita a zona do não ser, esquivando-se das suas funções públicas essenciais no campo da infraestrutura, da saúde, da educação e do lazer, por outro lado, o seu braço penal não dá trégua, conduzindo de forma contínua operações de extermínio da população negra nesses territórios (IPEA, Atlas da Violência 2020). Vemos essa dupla violência exercida pelo Estado, pela omissão e pelo excesso, no caso recente da morte de João Vitor Gomes da Rocha, em maio de 2020, durante a pandemia do novo coronavírus - circunstância que ampliou as desigualdades colocadas e o longo momento de ausência de políticas sociais articuladas de proteção e cuidado coletivo. O jovem foi assassinado durante uma operação das polícias militar e civil na Cidade de Deus, na zona oeste do Rio de Janeiro, durante a distribuição de cestas básicas pelo movimento Voluntários da Frente Cidade de Deus (Frente CDD).

Historicamente, a ausência do Estado tem impulsionado as/os moradoras/es das periferias a organizarem-se e construírem soluções criativas que não passam pela alçada do Estado - a título de exemplo, a distribuição de cestas básicas que se intensificou durante a pandemia a partir, sobretudo, de redes de cuidado pré-existentes. Justo no momento em que a Frente CDD cumpria uma função que deveria ser do Estado, o Estado ausente se fez presente, assassinando João Vitor Gomes da Rocha.

O caso de João Vitor não é um caso isolado levado a cabo por alguns membros desviantes da polícia, mas efeito de uma ação sistemática voltada para "fazer morrer" (Bento 2018) que tem na mira pessoas de uma cor de pele e territórios demarcados. Essa política planeada e reiterada de fazer morrer é visível, por exemplo, nos números: no Brasil, um jovem negro é assassinado a cada 23 minutos (Flacso 2016) e, segundo dados do $14^{\circ}$ Anuário Brasileiro de Segurança Pública, 2 em cada 3 pessoas presas são negras (Acayaba e Reis 2020). O território corporal da/o sujeita/o negra/o que habita as periferias do Rio de Janeiro torna-se o primeiro alvo das investidas coloniais (Rufino 2016) que a/o racializam, desumanizam e coisificam, transformando-as/os em alvos de suspeita, perseguição, vigilância, encarceramento e morte.

Os estereótipos atribuídos às masculinidades negras refletem e reproduzem as condições necessárias para o estabelecimento de políticas orientadas pelo confinamento e descartabilidade. Nos anos imediatamente após a dita abolição formal da escravidão no Brasil, o pânico e o medo branco (Azevedo 2004) tomou conta da elite brasileira, que passa a investir em políticas de branqueamento através 
da imigração europeia e de confinamento psiquiátrico e carcerário de sujeitas/os negras/os. Recém-saídas/os da condição de escravizadas/os, as/os sujeitas/os negras/os continuaram a ser submetidas/os a várias formas de violências física e simbólica, orientadas para fazê-las/os permanecer numa posição subordinada, para as/os conter ou eliminar (Souza 2013). Afinal, como destaca Maria Aparecida Silva Bento (2002 19), essa condição na qual se encontravam, em contraposição aos privilégios gozados pela elite, era fruto da apropriação indébita e de forma forçada dos seus bens concretos e simbólicos por parte desta elite, durante quase 400 dos 500 anos do Brasil, e continua até hoje nas mais variadas formas de expropriação.

Neste contexto, meninos e homens negros foram sistematicamente tachados como alvos privilegiados da violência estatal, através de representações raciais-genderizadas de criminosos, delinquentes, vagabundos e estupradores em potencial (Pinho 2019). Os estereótipos atribuídos às masculinidades negras, baseados na força física, mas não na força de caráter, seja entendida como intelectual ou moral, contribuíram para a ideia de que homens negros deveriam ter a sua mobilidade, força e vitalidade constantemente abatidas. No imaginário do Brasil pós-colonial, prevaleceu a ideia, ainda hegemónica entre as classes média e alta brancas brasileiras, de que os homens negros são essencialmente perigosos, irracionais, além de dotados de uma sexualidade desenfreada e ameaçadora. Conforme destaca Túlio Augusto Custódio (2019, 138), "ser homem negro envolve um ponto de marcação social que o coloca como alvo da violência estatal em grande parte perpetrada pela polícia".

Desse modo, as características em geral associadas ao gênero masculino, forjadas na lógica cisheteronormativa da branquitude, como poderosos, racionais, fortes, intelectuais, honrosos, não são extensivas nem aceitáveis para todos os homens, mas são aplicáveis apenas a um grupo particular, a elite masculina branca (Collins 2013). Homens negros, entre outros colocados como desviantes do padrão, são tidos como perigosos e não poderosos e penalizados quando exibem as ditas características masculinas (Collins 2013). Também são negadas, aos homens negros, as qualidades ditas masculinas de liderança, competência intelectual e racionalidade humana (Collins 2013). Fanon (2008) ajuda-nos a entender por que a sexualidade masculina negra não pode ser entendida no mesmo registo da masculinidade branca, supostamente universal (Collins 2013), considerando as implicações para a sustentação da supremacia branca. Na medida em que o negro não é tido como um homem, mas um sujeito macho (Lugones 2014), desumanizado, ele encontra-se impossibilitado de "exercer um lugar imagético e simbólico de Homem" (Custódio 2019, 143), o que revela as especificidades das dinâmicas de gênero na Améfrica Ladina (Gonzalez 1988; Lugones 2014; Vigoya 2018).

Assim, o sujeito negro é representado como truculento e brutal quando desestabiliza as fronteiras geográficas e simbólicas da cidade e como dócil e subserviente quando útil e servil aos interesses das classes privilegiadas (Vigoya 2018). De facto, as/os residentes das periferias do Rio de Janeiro só são toleradas/os 
quando atravessam os espaços da cidade de forma atomizada para trabalhar como empregadas domésticas, porteiros, motoristas e trabalhadores da construção civil para as classes abastadas. No entanto, os seus corpos são criminalizados, violados, contidos ou privados de liberdade sempre que os seus movimentos transgridem os limites da integração subalterna na cidade.

Abundam exemplos de moradoras/es de favelas cujos movimentos não são autorizados por aqueles que produzem e radicalizam as fronteiras de uma cidade partida. Todos os verões, os policiais militares param os carros e transporte dito público e revistam violentamente jovens com um perfil específico - negros e pobres - que vão dos bairros das zonas norte e oeste do Rio para o espaço dito o "mais democrático" da cidade, as praias da zona sul (Moura, Fernández e Page 2020). De facto, para jovens negros, muito antes da pandemia de COVID-19, as aglomerações já eram cerceadas, entendidas como suspeitas e explosivas, seja nos autocarros, nos bailes funk ou nos centros comerciais.

Tendo em vista este padrão de contenção e disciplinamento dos corpos das/os residentes nas periferias, numerosas atividades culturais e artísticas tornam-se alvo de controle, vigilância e repressão do Estado. Este foi o caso dos bailes funk, historicamente criminalizados e excessivamente associados ao tráfico de droga, à pornografia e à violência, deixando de lado inúmeros outros aspectos centrais do funk, como as suas dimensões estéticas, lúdicas e de sociabilidade (Sá 2014).

Outra instância da deslegitimação de vozes subalternas é oferecida por Osmundo Pinho $(2019,117)$ quando analisa o pagodão, um estilo musical que demoniza jovens negros desfavorecidos como "predadores bárbaros, com apetite sexual desmedido e perigoso, em vez de criadores e apreciadores de um gênero musical específico e o mais importante, como vítimas potenciais de um genocídio terrível, sancionado e promovido pelo Estado" (Pinho 2019, 125).

Todavia, o mesmo corpo atacado pelo Estado, seja na sua fisicalidade seja na sua subjetividade, arrisca-se em ações decoloniais (Rufino 2016). No território corporal, por meio dos seus saberes textualizados em performances diversas, emergem as possibilidades de novas inscrições que transgridem e rasuram os regimes de poder vigentes (Rufino 2016). Mesmo em contextos onde o Estado não fornece amparo para educação básica, saúde, transportes, saneamento, lazer e serviços culturais, os territórios periferizados abrigam novas formas de vida cotidiana, produzindo deslocamentos subjetivos desafiando a forma hegemónica de existência (Lacaz et al. 2015). Como argumenta Alessandra Lacaz et al. $(2015,63)$, "a miséria dá origem, não só a uma experiência de falta e necessidade, mas também a um método de produção que encontra outras formas materiais e imateriais de sustentação e reinvenção". E se tivermos qualquer possibilidade concreta de lidar com dinâmicas de violência doméstica que atinge desproporcionalmente mulheres e crianças, é preciso primeiro situar os determinantes da violência como linguagem imposta pelo Estado para mediar relações em territórios periferizados e as formas de enfrentamento forjadas a partir deste lugar. 
Através da arte, sujeitas/os negras/os interpelam o olhar que as/os fetichiza, exotiza e fixa num determinado lugar, constituindo-se em corpos que questionam e perturbam os regimes de visibilidade/invisibilidade vigentes (Rancière 2005; Fanon 2008; Vigoya 2018). Através da arte, residentes das favelas e periferias vêm alterando os regimes de visibilidade e invisibilidade que compõem a imaginação coletiva hegemónica. Ao fazê-lo, conferem e ampliam os significados políticos da estética, pois perturbam as fronteiras dominantes entre o invisível/irrelevante e o visível/relevante (Rancière 2005). A arte tem o potencial de, assim, contribuir para assegurar que as/os sujeitas/os periferizadas/os tratadas/os como inexistentes possam afirmar-se e interferir nas representações dominantes de gênero e raça e abrir fraturas nas estruturas sociais (SupGaleano 2015). Enquanto o olhar branco categoriza o corpo negro a partir de um imaginário racista, produz-se arte onde este corpo, por meio de linguagens artísticas diversas, excede os sentidos que lhe são atribuídos, não se deixando capturar ou traduzir pelos estereótipos coloniais sobre seus (não) seres e (não) saberes. Através da arte, torna-se possível desafiar o olhar branco que procura colocá-las/os em estereótipos (Vigoya 2018, 117-8) e imagens controladoras (Collins 2013).

Contra práticas coloniais de desagregação, desenraizamento e ruptura de laços afetivos perseguidas pelos colonizadores e pelas elites pós-coloniais, o fazer artístico que reúne jovens das periferias do Rio de Janeiro reconecta, alimenta a autoestima, reata elos por meio do amor (Emicida 2019), do compartilhamento de vivências e histórias que se cruzam e produz novos envolvimentos. Por meio sobretudo da dança e da música, base cultural e forma de comunicação central para a diáspora africana (Glissant 1989; Vigoya 2018), artistas periféricas/os recuperam e reinventam as suas histórias, fazendo da arte, vida diária, o meio pelo qual sobre/ /vivem e resistem, e fazendo da vida, arte. E quanto mais vinculadas/os estas produções artísticas os/as tornam, mais a arte tem o potencial de desafiar os padrões vigentes de masculinidades violentas criadas no seio de uma sociedade racista e patriarcal.

\section{O passinho ${ }^{1}$ como campo de disputa e prática de reinvenção de relações de gênero e padrões de masculinidades}

Após a introdução que apresentámos para situar as re/produções de violências raciais-genderizadas no contexto brasileiro, especialmente no que tange à

\footnotetext{
O passinho é um estilo de dança que tem início nos bailes funk das periferias do Rio de Janeiro e que se caracteriza por coreografias improvisadas que se destacam pelos movimentos acelerados dos pés das/os dançarinas/os. Para mais informações ver: "A História do Passinho e sua chegada às Olimpíadas de 2016", Disponível no endereço: A História do Passinho e sua chegada às Olimpíadas de 2016 | Combate Racismo Ambiental [Consultado em 27 de março de 2021].
} 
estruturação da linguagem da violência redimensionada a partir da posicionalidade de jovens negros, chegamos ao passinho, movimento, dança, prática cultural e artística produzida em favelas e periferias, como campo potencial para diálogo acerca de desigualdades territoriais, raciais e de gênero - projeto de pesquisa-ação GlobalGRACE, Gênero e Culturas Globais de Igualdade no Brasil.²

O projeto internacional, liderado por uma equipa de pesquisadoras/es de Goldsmiths, University of London, é integrado por académicas/os e organizações de sociedade civil do Bangladesh, Brasil, México, Filipinas e África do Sul, que vêm pesquisando, mobilizando, produzindo e compartilhando diferentes linguagens estéticas, artísticas e curatoriais com potencial para desafiar quotidianamente as relações de poder dominantes e para construir sociabilidades alternativas centradas na afirmação da vida. No Brasil, o projeto é desenvolvido coletivamente através da parceria entre o Instituto de Relações Internacionais da PUC-Rio e as organizações não-governamentais UNIperiferias/Instituto Maria e João Aleixo, Instituto Promundo e Observatório de Favelas, incidindo a pesquisa sobre o potencial de experiências artísticas protagonizadas por sujeitos/as periféricos/as no Rio de Janeiro, como o passinho, para produzirem novas masculinidades, transgredindo os padrões hegemônicos de raça e gênero.

Nos imaginários hegemónicos forjados no racismo/sexismo institucional, os territórios periferizados foram concebidos como uma espécie de "estado de natureza" ou espaço de ausências, como teorizado pelos contratualistas. Neste sentido, são lidos como vazios culturais e artísticos, espaços de carências e fatalidades, ou como produtores de uma cultura menor, desviada. Estas representações pautadas convergem para a ideia de que a cidade formal e as suas/seus moradoras/es económica e socialmente privilegiadas/os são aquelas/es que produzem conhecimento científico e expressões culturais e artísticas legítimas, que devem ser transportadas para as periferias a fim de preencher o vácuo cultural ou mesmo corrigir/salvar as/ /os sujeita/os periféricas/os das suas culturas tidas como atrasadas e violentas (Moura, Fernandez e Page 2020).

Contra esse imaginário que reduz a ideia de periferia a um espaço homogéneo estereotipado, há um conjunto de expressões artísticas produzidas por sujeitas/os moradoras/es de favelas e periferias que afirmam outros olhares para a arte que é produzida, que circula, que dá sentido à vida e que resiste nas periferias da cidade. As contribuições de Jailson de Souza e Silva e Jorge Barbosa (Fernandes, Silva e Barbosa 2018), fundadores do Observatório de Favelas, sobre o "paradigma da potência" são provocações neste sentido. Enquanto as narrativas hegemónicas olham para os espaços periferizados e suas/seus moradoras/es a partir do "paradigma da ausência", levando em conta o que eles não têm, as suas ditas precariedades e carências, Silva e Barbosa propõem uma forma alternativa de interpretar

$2 \quad$ Ver https: / / www.globalgrace.net/ 
as práticas sociais presentes nas periferias, que valoriza a sua inventividade e as suas expressões estéticas variadas (ibid.). É nesse sentido que Boaventura de Sousa Santos $(2002,249)$ propõe que as experiências produzidas como ausentes sejam libertadas dessas relações de produção e se tornem presentes, ampliando o campo de experiências credíveis existentes.

Assim, chegamos ao passinho, como expressão artística e estética de favelas e periferias do Rio de Janeiro, que pode ser caminho para discutirmos, produzirmos e visibilizarmos o potencial transformador de práticas artísticas de favelas e periferias a partir das lentes de gênero, em particular as das masculinidades. Como é que a arte produzida nas e pelas periferias vem produzindo subjetividades que rearticulam e subvertem quotidianamente os discursos e práticas da masculinidade hegemónica, branca e cisheteronormativa? Como é que intervenções artísticas e culturais perturbam o regime interseccionado de desigualdade de gênero que nos estrutura e que oprime desproporcionalmente a população negra e periferizada? De que forma tais produções artístico-culturais desafiam construções estereotipadas de gênero?

Essas perguntas foram discutidas, sentidas e partilhadas por meio de corpos pulsantes, cada qual em busca da sua manha. Essas perguntas inquietaram, (co) moveram e (co)produziram deslocamentos subjetivos e físicos num grupo de dançarinos da Companhia de Dança Passinho Carioca.

O Projeto Passinho Carioca é uma iniciativa articulada por Thiago de Paula, jovem morador do Conjunto de Favelas da Penha, zona norte da cidade do Rio de Janeiro, que, desde 2015, tem como objetivo formar jovens de favelas e periferias em expressões artísticas diversas, como dança, teatro e canto, com foco especial no movimento do passinho. Se há uma estrutura social racista e sexista que insiste em desqualificar jovens de territórios periferizados e que apresenta poucas alternativas formativas e profissionais emancipadoras, o Passinho Carioca, assim como muitos projetos culturais e sociais de favelas e periferias, cria alternativas a partir das artes para as vulnerabilidades impostas e, ao passo que profissionalizam e ampliam as possibilidades económicas dos seus participantes, garantem espaços de diálogo sobre os processos que mobilizam a cidade e as suas estruturas.

No caso do Passinho Carioca, foram já registados/as cerca de 30 jovens como artistas ao longo dos últimos 5 anos, passo importante para a inserção no universo do trabalho digno em opção aos subempregos. Além de uma companhia de dança homónima, o projeto atende em média 2.000 jovens através de oficinas e eventos regulares, como a Rabisca Battles, ambos realizados no equipamento público cultural Arena Carioca Carlos Roberto de Oliveira - Dicró ${ }^{3}$ sob gestão do Observatório de Favelas. Com 6 anos de vida, a companhia já se apresentou em palcos como Rio Parada Funk, Rock in Rio e Theatro Municipal, e conta no seu currículo com o

https: / / arenacariocadicro.org.br/ 
espetáculo autoral "Resistência: Um Sonho se Realiza!", que circulou na Rede SESC Rio. Recentemente, uma parte das/os bailarinas/os viajou para a Grécia, para ensinar os movimentos do Passinho a bailarinas/os do espetáculo "The Birds" do Diretor Nikos Karathanos, através da Onassis Foundation.

Com a direção geral do coletivo de dança do Conjunto de Favelas da Maré, Mulheres ao Vento, liderado por Andreza Jorge e Simonne Alves, que também assinam a direção cénica e de movimento, a Companhia Passinho Carioca construiu, durante o ano de 2020, no contexto das ações brasileiras do projeto GlobalGRACE, o espetáculo $\mathrm{Na}$ Manha. A experiência é fruto de uma residência formativa sobre masculinidades, facilitada pelas próprias diretoras e por pesquisadoras/es do Instituto Promundo, Linda Cerdeira, Rafaela Cotta e Luciano Ramos, e que envolveu espaços interligados de reflexões de natureza teórica e prática.

Perante o desafio, percebemos a prática artística, nos espaços de preparações, ensaios corporais e diálogos gerais sobre texto e estética, como um campo fértil de rearticulação e desestabilização de termos e lugares (ou não lugares) que, em geral, a sociedade racista patriarcal capitalista atribui incessantemente a jovens moradoras/es de favelas e periferias, na sua maioria negra. Os laboratórios de criação foram atravessados pelos desafios da pandemia global do novo coronavírus, que rearticularam a produção e gravação do espetáculo em formato de videodança, encenando diálogos através de cenas gravadas de forma independente, dadas as restrições do distanciamento social. Assim, Na Manha permanece como uma obra-testemunha da potência inovadora das periferias, tanto em termos tecnológicos, quanto artísticos, conceptuais e políticos. O espetáculo online estreou, no âmbito do projeto GlobalGRACE, nos dias 18 e 19 de setembro de 2020 no canal oficial da Arena Carioca Dicró ${ }^{4}$, onde a residência foi localizada.

\section{Na manha: o que é falar de masculinidades?}

Mas, afinal, o que é na manha? As/os dançarinas/os da Cia. Passinho Carioca explicam que, na gramática do passinho, manha faz referência à possibilidade de cada pessoa ter a sua "onda", uma forma própria de se expressar e dançar.5 Ao reivindicarem as suas manhas, as/os dançarinas/os apresentam, no desenrolar do espectáculo, reivindicações das suas identidades, a possibilidade de dançarem, se vestirem e se comportarem como bem entenderem, posicionando-se, dessa forma, na contramão de uma sociedade que insiste em disciplinar e regular expressões, percepções e identidades, inclusive as de gênero.

https:/ / www.youtube.com/c/ArenaCariocaDicro

Bate-papo com os artistas disponível em https: / / www.youtube.com/ watch?v=u-8fuW71sO0\&l ist=PLi7fSprtgAgeasIXNDNm8o0RBYjkAtJ0g\&index=3 [Consultado em 27 de março de 202]. 
Ao reivindicarem as suas manhas, essas/es jovens artistas expressam, por meio das suas performances, ${ }^{6}$ formas de transgredir as fronteiras de gênero e padrões de masculinidades internalizadas, até mesmo no universo do passinho; falam de formas de desafiar as fronteiras geográficas e simbólicas de uma cidade que diz como e por onde os seus corpos devem transitar e como devem performar; questionam os limites classistas, racistas e sexistas da cidade que lhes reserva empregos precarizados e uma integração subalterna voltada para a reprodução dos interesses das classes hegemónicas. Em suma, ao performarem livremente as suas manhas, esse jovem grupo de dançarinas/os em diálogo com duas jovens diretoras, mulheres negras e de origem periférica, reivindicam, na produção do $\mathrm{Na}$ Manha, um projeto de vida, de humanização, que resiste ao projeto de morte e desumanização em curso na sociedade brasileira há mais de 500 anos.

Na leitura do Na Manha, percebemos nomeada uma potente criação coletiva: ela expressa singularidades, uma forma única do corpo se expressar, ela dá nomes próprios a cada um/a das/os dançarinas/os - Ayesca Mayara Souza, Daniel Henrique Costa Rocha, Mayra de Farias Lima, Nayara Costa da Silva, Richard Silva dos Santos e Walcir Silva De Oliveira. Nesse processo, as/os dançarinas/os resistem aos lugares e papéis social e violentamente construídos para os seus corpos habitarem. Corpos atravessados por marcadores de gênero, sexualidade, raça, classe, idade e território, que têm sido historicamente crimininalizados, desumanizados, despersonalizados, folclorizados, contidos e enclausurados, desestabilizam, através dos seus saberes e fazeres, esses rótulos e caixas que os aprisionam, genderizam e racializam. E assim, abrem a possibilidade de afirmar a dignidade plena de cada pessoa, entendendo que essa dignidade só tem como ser vivida em relação.

Meninos e homens negros que foram socializados, como bem nos ensina bell hooks (2004), numa cultura racista e sexista que não lhes permite sentir ou expor as suas vulnerabilidades e dos quais se exige uma masculinidade violenta e autoritária; por meio de $\mathrm{Na}$ Manha, como síntese de práticas e propostas artísticas diversas, expressam uma complexidade de emoções que é da natureza humana em sociedade. Considerando, como reiteramos na introdução, a política dominante que assassina e criminaliza jovens negras/os moradoras/es de favelas e periferias no contexto de práticas genocidas e de representações hegemónicas degradantes e estigmatizantes, que negam direitos fundamentais - inclusive, em muitos casos, a vida - o projeto coletivo $\mathrm{Na}$ Manha manifesta possibilidades para esses corpos serem colocados disponíveis para uma cultura própria, centrada na afirmação da vida.

\footnotetext{
Empregamos a palavra "performance" para nos referirmos, de um modo geral, ao ato de dar forma, de criar, tal como utilizado no campo das artes e conforme apontado por Carla Rodrigues em "Performance, gênero, linguagem e alteridade: J. Butler leitora de J. Derrida", Sexualidad, Salud y Sociedad 10, 2012.
} 
O que entendemos dessa experiência é que esse grupo de jovens, enquanto dança, faz política, teoriza, questiona, vive, sente e altera os regimes de visibilidade e invisibilidade que conformam o nosso senso comum e as hierarquias colocadas, em particular no que concerne às masculinidades hegemónicas pautadas no exercício da violência e na subordinação do feminizado. O espetáculo, que dura cerca de 19 minutos, manifesta um desafio ao que Mara Viveros Vigoya chama de "a ideia de uma masculinidade abstrata, universal e desencarnada" (Vigoya 2018, 24), mobilizando reflexões e provocando fissuras em padrões dominantes, transmitindo, a partir das escolhas estéticas que configuraram a sua linguagem artística, mensagens dissonantes que apresentam alternativas para o pensar e atuar cidades, gêneros, masculinidades e juventudes, partindo de perspectivas racializadas e territorialmente informadas.

O resultado, apresentado nas cenas gravadas do $\mathrm{Na}$ Manha, é uma assertiva afirmação da "diversidade e heterogeneidade das masculinidades, mas também as desigualdades, tensões, ambiguidades e contradições que caracterizam" (Vigoya 2018 , 24) o existir, do nascimento à vida em coletividade, uma vez que as masculinidades se constituem em relações sociais - de classe, idade, território, raça, sexualidade, em formas imbricadas com o gênero. Neste sentido, o grupo sugere, a quem o assiste, caminhos para a mobilização de reflexões sobre hegemonias, exercícios de tensionamento de normas, especialmente de gênero, que situam as suas corporeidades em contextos diversos, inclusive na dança, procurando incluírem-se ou confrontando o que está posto.

$\mathrm{Na}$ Manha reflete sobre padrões, normas e pactos imbricados de gênero que as/os jovens dançarinas/os da Cia. Passinho Carioca redimensionam através dos movimentos dos seus corpos. Na reflexão do urbanista David Harvey,

Na qualidade de 'máquina desejante' capaz de criar ordem não apenas em seu próprio interior, mas também em seu entorno, o corpo humano é ativo transformador em relação aos processos que o produzem, sustentam e dissolvem. Logo, pessoas corporificadas dotadas de capacidades semióticas e vontade moral tornam seu corpo um elemento fundacional naquilo que há muito chamamos de "corpo político". (Harvey $2012,138)$

Neste sentido, temos oportunidade de dialogar com as proposições políticas apresentadas no Na Manha - tido de extrema alteridade em relação às curiosidades fetichizantes que há séculos se direcionam para periferias e suas sujeitas e sujeitos e as/os desqualificam como lugares e pessoas produtores de conhecimento no contexto do projeto colonial de ciência. Se, por um lado, o corpo se constitui enquanto território moldado por práticas representacionais que operam a sociedade, já que "nenhum corpo humano é isento de processos sociais de determinação" (Harvey 2012, 140), ele é, ao mesmo tempo, solo fértil de processos transformadores e questionadores, chão de resistências, desejos de mudanças, rebeliões e revoluções. 
Em seu curso, somos convidadas/os a questionamentos sobre como pessoas in-corpo-ram papéis e relações sociais de gênero, classe, territorialidade, etários e raciais e que brechas e tensões podem ser acessadas no processo permanente pela descolonização das nossas formas de ser, poder, saber, sentir, performar, dançar e viver. E, assim, há oportunidade de mapearmos transgressões, no sentido das suas potências políticas de transformação na sociedade (Balbi 2018), que desautorizam os muitos exercícios de dominação violenta que nos estruturam e que atingem de forma imbricada as juventudes moradoras de favelas e periferias. Nesse sentido, pensar masculinidades implica necessariamente repensar os termos através dos quais os instrumentos de poder são forjados e ativados e os seus efeitos desproporcionais em todas/os nós. Não se pode enfrentar a opressão sem conceber o que a sustenta: o privilegiar de formas de ser e estar no mundo condizentes com projetos de sociedade erguidos pela estrutura escravocrata da modernidade colonial. Comprender a genderização da violência a partir da posicionalidade de meninos e homens negros é ampliar a nossa perspectiva sobre as suas condições de possibilidade e instrumentalizações diversas.

\section{Considerações finais}

Historicamente, em territórios periferizados, a cultura e a arte são caminhos para invenção de estratégias comunitárias para garantia de direitos fundamentais. O que se observa são elementos da prática cultural e artística atuando como instrumento "político, económico, social e territorial, confirmando o papel da arte como central na ampliação das possibilidades existenciais de múltiplos grupos sociais" (Silva e Santos 2020, 74). As periferias, como Silva $(2015,14)$ defende,

criam experiências que podem ser centrais para a democratização da cidade, na superação das formas de reprodução da desigualdade, das hierarquias e de processos de subjetivação que levam o indivíduo ao encapsulamento e, muitas vezes, à depressão e aniquilação social.

Jovens periferizadas/os instituem a arte como possibilidade de criação de novos reais para si, suas corporeidades, suas identidades (raciais, de gênero, de classe, etárias, de sexualidade e territoriais) e suas condições materiais e simbólicas de vida - e, portanto, também trabalho.

Nossa breve jornada neste artigo, diante do contexto introdutório e do diálogo com a experiência singular da Companhia Passinho Carioca, aponta para a força do trabalho artístico desenvolvido por moradoras/es de favelas e periferias como campo de aprendizagens para trilharmos socialmente a transformação das desigualdades e o alargamento das práticas democráticas, mesmo diante de tantas violências ampliadas e institucionalizadas. Fica registado aqui o convite para 
assistirem ao espetáculo Na Manha em forma de videodança, que estará disponível com acesso aberto a partir de junho 2021 no canal oficial do GlobalGRACE Brasil. ${ }^{7} \mathrm{Na}$ Manha, assim como um conjunto grande e ainda pouco re/conhecido de iniciativas artístico-culturais protagonizadas por pessoas oriundas de favelas e territórios periferizados, representa uma

aposta política no sentido de articulações e ações estéticas efetivas possíveis, pautadas por uma diversidade de sujeitos/as e territórios historicamente invisibilizados/as, os/ as quais a maior parte dos espaços institucionais, sejam eles da arte ou não, ignoram, rejeitam e/ou reservam um lugar menor. (Silva e Santos 2020, 80)

Neste sentido, consideramos que este espetáculo se apresenta como mais um movimento de resistência e criação diante da complexidade de um país marcado por um contínuo genocídio e epistemicídio e, nas palavras da Lélia Gonzalez (1988, 69), "cujas formações do inconsciente são exclusivamente europeias, brancas". Re/conhecer e redimensionar as heranças indígenas e africanas que constituíram esse território é afirmar a possibilidade de uma efetiva descolonização e democratização do nosso país, que movimentos indígenas e negros vêm mantendo vivo, das mais diversas formas, através de uma luta plurissecular por liberdade.

Pensar as relações de gênero neste contexto é pensar as múltiplas formas em que as hierarquizações da nossa humanidade são articuladas e renovadas diariamente. Os padrões de masculinidades valem-se precisamente nesse campo, estruturando os termos e pactos que reproduzem o sistema de gênero binário forjado na lógica da branquitude, da cisheteronormatividade, entre outras heranças do projeto moderno colonial. Questionando a sua in-corpo-ração, é possível implicarmo-nos na permanente disputa pela sua transformação, abrindo caminhos para um mundo em que a humanidade das pessoas não sirva como moeda de troca em sistemas de exploração, opressão, expropriação e violências institucionais e intersubjetivas que negam a possibilidade de viver em relações de respeito.

\section{Referências bibliográficas}

Acayaba, Cintia, e Tiago Reis. 2020. "Proporção de negros nas prisões cresce $14 \%$ em 15 anos, enquanto a de brancos cai 19\%, mostra Anuário de Segurança Pública." G1. Disponível em https://g1.globo.com/sp/sao-paulo/noticia/2020/10/19/em-15-anos-proporcao-de-negros-nas-prisoes-aumenta-14percent-ja-a-de-brancos-diminui19percent-mostra-anuario-de-seguranca-publica.ghtml [Consultado em 09 de janeiro de 2021].

Azevedo, Celia Maria Marinho. 2004. Onda negra, medo branco: o negro no imaginário das elites - século XIX. São Paulo: Annablume.

\footnotetext{
Vem em: https:/ / www.youtube.com/ channel/UCWNQ116lhn3nd0isK-gggdg.
} 
Balbi, Dani. 2018. "Gênero e sexualidade: sujeitos periféricos em sua dimensão corpóreo-política" [vídeo]. In Significações da periferia: representações, confluências e transgressões, organizado por UNIperiferias, Disponível em https:/ / www.youtube.com/watch?$\mathrm{v}=\mathrm{ey} 5 \mathrm{KyG} 32 \mathrm{~J}$ tk

Bento, Maria Aparecida Silva. 2002. "Branqueamento e branquitude no Brasil." In Psicologia social do racismo - estudos sobre branquitude e branqueamento no Brasil, organizado por Iray Carone e Maria Aparecida Silva Bento, 25-58. Petrópolis, RJ: Vozes.

Bento, Berenice. 2018. "Necrobiopoder: Quem pode habitar o Estado-nação?" Cadernos Pagu 53. DOI: https://doi.org/10.1590/18094449201800530005. Disponível em https:/ / periodicus.sbu.unicamp.br/ojs / index.php/cadpagu/article/ view / 8653413/18511 [Consultado em 9 de janeiro de 2021].

Collins, Patricia Hill. 2013. On Intellectual Activism, Philadelphia: Temple University Press.

Custódio, Túlio Augusto. 2019. "Per-vertido Homem Negro: reflexões sobre masculinidades negras a partir de categorias de sujeição." In Diálogos Contemporâneos sobre Homens Negros e Masculinidades, organizado por Henrique Restier e Rolf Malungo de Souza, 131-162. São Paulo: Ciclo Contínuo Editorial.

Emicida. 2019. AmarElo - É Tudo pra Ontem. Disponível em https:/ / www.youtube.com/ watch?v=FQ9hCN0ZYSg. [Consultado em 09 de janeiro de 2021]

Fanon, Frantz. 2008. Pele Negra, Máscaras Brancas. Salvador: Editora da Universidade Federal da Bahia.

2004. The Wretched of the Earth. New York: Grove Press.

Flacso. 2016. Mapa da Violência. Disponível em http: / / flacso.org.br/?p=16029. [Consultado em 09 de janeiro de 2021].

Fernandes, Fernando, e Jailson Souza e Silva e Jorge Barbosa. 2018. "O Paradigma da Potência e a Pedagogia da Convivência." Revista Periferias 1: Editorial. Disponível em https: / / revistaperiferias.org/materia / o-paradigma-da-potencia-e-a-pedagogia-daconvivencia/. [Consultado em 09 de janeiro de 2021].

Glissant, Edouard. 1989. Discourse. Selected Essays. Charlottesville VA: University Press of Virginia.

Gonzalez, Lélia. 1988. "A categoria político-cultural de amefricanidade." Tempo Brasileiro, 92 (93): 69-82.

Harvey, David. 2012. Espaços de esperança. São Paulo: Edições Loyola Jesuítas.

hooks, bell. 2004. We Real Cool: Black Men and Masculinity. New York: Routledge.

IPEA - Instituto de Pesquisa Econômica Aplicada. 2020. Atlas da Violência. Disponível em www.ipea.gov.br. [Consultado em 27/03/2021].

Lacaz, Alessandra Speranza, Silvana Mendes Lima, e Ana Lúcia Coelho Heckert. 2015. "Juventudes Periféricas: Arte e Resistências no Contemporâneo." Psicologia e Sociedade, 27(1): 58-67. DOI: https: / / doi.org/10.1590/1807-03102015v27n1p058.

Lugones, Maria, 2014. "Rumo a um feminismo descolonial." Revista Estudos Feministas 22(3): 935-952. DOI: https:/ / doi.org/10.1590/\%25x

Mbembe, Achile. 2011. Necropolítica. Santa Cruz de Tenerife: Editorial Melusina.

Moura, Tatiana, Marta Fernández, e Victoria Page. 2020. "Power from the Peripheries. Art, Culture and Masculinities in Rio de Janeiro." In Theorising Cultures of Equality, organizado por Suzanne Clisby, Mark Johnson e Jimmy Turner, 158-170. London: Routledge.

Pinho, Osmundo. 2019. "O corpo do homem negro e a guerra dos sexos no Brasil." In Diálogos contemporâneos sobre homens negros e masculinidades, organizado por Henrique Restier e Rolf Malungo de Souza, 105-130. São Paulo: Ciclo Contínuo Editorial. 
Rancière, Jacques. 2005. A partilha do sensível - Estética e Política. São Paulo: EXO Experimental org. / Editora 34.

Rufino, Luiz. 2016. "Performances afro-diaspóricas e decolonialidade: o saber corporal a partir de Exu e suas encruzilhadas." Antropolitica - Revista Contemporânea de Antropologia, 40:54-80. DOI: https:/ / doi.org/10.22409/antropolitica2016.1i40.a451

Sá, Simone Pereira. 2014. "Apropriações low-tech no funk carioca: a Batalha do Passinho e a rede de música popular de periferia." Fronteiras - estudos midiáticos 16(1): 28-37. DOI: 10.4013 / fem.2014.161.04

Santos, Boaventura de Sousa. 2002. "Para uma sociologia das ausências e uma sociologia das emergências." Revista Crítica de Ciências Sociais 63: 237-280. DOI: https:// doi. org / $10.4000 /$ rccs. 1285

Silva, Isabela Souza, e Jean Carlos de Souza Santos. 2020. “Galpão Bela Maré: sentidos e práticas curatoriais urgentes." Revista Poiésis 21(35): 71-86. DOI: https: / / doi.org/10.22 409 / poiesis.v21i35.40411

Silva, Jailson de Souza. 2015. "As práticas culturais das periferias mobilizando a cidade." In 40 vozes do Rio: avaliações e propostas culturais para uma cidade única, organizado por Carlos Alberto Masser e Carla Branco, 142-146. Rio de Janeiro: E-papers.

Souza, Rolf Malungo de. 2013. "Falomaquia. Homens negros e brancos e a luta pelo prestígio da masculinidade em uma sociedade do Ocidente." Antropolítica - Revista Contemporânea de Antropologia 34: 35-52. DOI: https:/ / doi.org/10.22409/ antropolitica2013.0 i34.a168

SupGaleano. 2015. "El Muro y la Grieta. Primer Apunte sobre el Método Zapatista." Enlace Zapatista. Disponível em http:/ /enlacezapatista.ezln.org.mx/2015/05/03/el-muroy-la-grieta-primer-apunte-sobre-el-metodo-zapatista-supgaleano-3-de-mayo/. [Consultado em 09 de janeiro de 2021].

Vigoya, Mara Viveros. 2018. As Cores da Masculinidade. Experiências interseccionais e práticas de poder na Nossa América. Rio de Janeiro: Papéis Selvagens.

Andréa Gill. Professora do Instituto de Relações Internacionais da Pontífica Universidade Católica do Rio de Janeiro (PUC-Rio). Doutora em Ciência Política e Pensamento Cultural, Social e Político pela University of Victoria (Canadá) e pesquisadora pós-doutora da rede GlobalGRACE. Pesquisadora associada do Núcleo Interdisciplinar de Reflexão e Memória Afrodescendente e pesquisadora docente da UNIperiferias.

Endereço eletrónico: andrea.b.gill@gmail.com

Isabela Souza da Silva. Doutoranda em Geografia na Universidade Federal Fluminense (UFF), Mestre em Planejamento Urbano e Regional pela Universidade Federal do Rio de Janeiro (UFRJ) e Bacharel em Turismo pela Universidade Federal do Estado do Rio de Janeiro (UNIRIO). Nasceu e cresceu na Maré, e desde 2011 é parte da equipe do Observatório de Favelas.

Endereço eletrónico: isabela@observatoriodefavelas.org.br

Marta Fernández. Professora Adjunta do Instituto de Relações Internacionais da Pontífica Universidade Católica do Rio de Janeiro (PUC-Rio) e pesquisadora do 
Projeto Internacional GlobalGRACE (Global Gender and Cultures of Equality). Suas principais áreas de interesse se centram em estudos pós-coloniais e decoloniais, estética, violência e resolução de conflitos.

Endereço eletrónico: martafygarcia@gmail.com

Tatiana Moura. Investigadora do Centro de Estudos Sociais da Universidade de Coimbra, Coordenadora do Promundo Portugal e Diretora Associada do Instituto Maria e João Aleixo (Maré, Rio de Janeiro, Brasil). Entre 2011 e 2019 foi Diretora Executiva do Instituto Promundo (Rio de Janeiro, Brasil).

Endereço eletrónico: t.moura@promundoglobal.org

Artigo recebido a 14 de janeiro e aceite para publicação a 08 de março de 2021. 